International Review of Research in Open and Distributed Learning Volume 22, Number 4

November - 2021

\title{
How Are We Doing with Open Education Practice Initiatives? Applying an Institutional Self-Assessment Tool in Five Higher Education Institutions
}

Tannis Morgan ${ }^{1}$, Elizabeth Childs ${ }^{2}$, Christina Hendricks ${ }^{3}$, Michelle Harrison ${ }^{4}$, Irwin DeVries ${ }^{5}$, and Rajiv Jhangiani ${ }^{6}$ ${ }^{1}$ Vancouver Community College, ${ }^{2}$ Royal Roads University, ${ }^{3}$ University of British Columbia, ${ }^{4,5}$ Thompson Rivers University, ${ }^{6}$ Kwantlen Polytechnic University

\begin{abstract}
This collaborative self-study examines how five higher education institutions in British Columbia (BC), Canada, have achieved momentum with openness and are implementing and sustaining their efforts. A goal of this research was to see whether an institutional self-assessment tool-adapted from blended learning and institutional transformation research-can help to assess how an institution has progressed with its open education initiatives. By adopting both an appreciative and a critical approach, the researchers at these five $\mathrm{BC}$ institutions compared the similarities and differences between their institutional approaches and the evolution of their initiatives. The paper includes discussion of how a self-assessment tool for institutional open education practices (OEP) can be applied to OEP initiatives at an institutional level and shares promising practices and insights that emerge from this research.
\end{abstract}

Keywords: open education practices, self-assessment tool, institutional initiatives, blended learning, institutional transformation 


\section{Introduction}

British Columbia (BC), Canada, has a well-established government-supported open education resources (OER) initiative that began in 2003 and subsequently became an open textbook initiative in 2012. Through BCcampus, the 25 public postsecondary institutions in BC are supported by OER grants, professional development, and research opportunities, as well as infrastructure for open textbook publishing. Since 2012 the Ministry of Advanced Education and Skills Training has invested \$5.91 million in the support of Open Education in British Columbia, with the Hewlett Foundation investing an additional \$1.95 million since 2014. This has resulted in approximately $\$ 26$ million in student textbook savings, and a collection of curated and peer-reviewed textbooks has grown to over 360 items. Given the recent progress with OER and resultant open education practices (OEP) in $\mathrm{BC}$, it is timely to address what success factors contributed to the recent momentum observed at five of the institutions. Therefore, we, as researchers from five public postsecondary institutions in $\mathrm{BC}$, conducted a collaborative study based on our respective institutions.

Our research is informed by a position that openness, and open education, is a type of institutional change initiative and that there is value in looking at research on other types of institutional change initiatives for insights into success factors. As Weller et al. (2018) have noted, open education research has developed largely as islands of subtopics disconnected from each other, with the result that open education research has ignored previously published knowledge. Since institutional level studies on openness are a nascent area of inquiry, the following question arises: Can research on blended learning as institutional initiative (Graham et al., 2013; Lim \& Wang, 2017) and research on broader institutional transformation (Kezar \& Eckel, 2002) lend insights into potential success factors for institutional OEP initiatives? This article will discuss the themes emerging from our investigation of the theoretical and practical applications of an institutional self-assessment tool that identifies gaps and attends to the success factors for institutionallevel OEP initiatives.

\section{Literature Review}

OEP is a term that is continually contested and redefined. In this study, we define OEP as "a broad descriptor that includes the creation, use and reuse of OER, open pedagogies, and open sharing of teaching practices” (Cronin, 2017, p. 16). As explained in Inamorato dos Santos (2019),

Open education is about a set of practices that together can lead higher education to be more inclusive, in line with societal changes, and also to be more innovative in terms of making the most effective use of teaching and educational resources, research and students' services. These practices are often referred to as open educational practices. (p. 8)

While considerable enthusiasm exists for the benefits of OEP, researchers and practitioners express ongoing concern about the sustainability of openness (Friesen, 2009; Rolfe, 2012; Wiley, 2007) and the growing realities of invisible labour in open education (Watters, 2018) and in academia more broadly (SSFN-RIG, 2017). Questions have been raised about whether grassroots open education efforts, led by keen faculty or institutional champions, are sufficient to expand OEP sustainably across an institution and whether the kind of support needed at all levels of the institution to do this is available. Furthermore, there 
is increasing recognition of the importance of examining institutional-level efforts to achieve openness as a means to better grow, sustain, and evaluate the efforts. The recent report Achieving the Dream (Griffiths et al., 2020) states, "OER adoption is a strategic institutional initiative. Units across campus must work in coordination to plan and execute the development of OER courses across departments as well as related policies and practices for service units, advising, bookstores, and administrative functions" (p. 8). This report concludes that senior administrative support and faculty development and support are important to build momentum and remove obstacles to ensure scaling up of efforts. Similarly, in a recent US study, Spilovoy et al. (2020) found that faculty awareness of OER was higher when an OER initiative was implemented at an institutional level (p. 3).

As institutions move to consider implementing or assessing open education initiatives, it is crucial that they understand the characteristics and potential success factors as part of the process. Hannon et al. (2014) observe that bootstrapping - where local OER initiatives serve as a catalyst to institutional OEP-can occur, but they note that "it is critical that new arrangements are established and nurtured with diverse socialtechnical entities, including participants, procedures, policies and technologies alike" (p. 148). Inamorato dos Santos et al. (2016) offer a 10-dimension framework of strategies for higher education institutions and policy makers to "promote transparency for collaboration and exchange of practices among higher education institutions" (p. 2), noting that without such a tool, institutional stakeholders may overinvest in some areas and overlook others. We share this concern and, in our study, provide a rationale for seeking to assess the institutional effort as a whole in a balanced way. Inamorato dos Santos et al. (2016), in their framework, identify six core dimensions (access, content, pedagogy, recognition, collaboration, and research) and four transversal dimensions (strategy, technology, quality, and leadership) of promoting and sharing open education.

Blended learning initiatives share similarities with open education initiatives in their endeavour to introduce and sustain pedagogical change and enable positive impacts on teaching and learning. They are often positioned as an academic innovation or institutional change (Garrison \& Vaughan, 2013; Taylor \& Newton, 2013) that requires many stakeholders to engage at all levels of the institution.

In our review of eight case studies of institutional blended learning, we identified common components or facilitators that characterize successful blended learning initiatives. In particular, a recent UNESCO publication (Lim \& Wang, 2017) notes that "sustainable and scalable blended learning practices in HEIs must begin with institutional leaders adopting a holistic approach towards driving and supporting these practices" (p. 22). Through examining six case studies from Asia-Pacific universities of how these universities built the capacity to drive, sustain, and scale their blended learning initiatives, Lim and Wang (2017) arrive at a self-assessment tool that includes 17 components across eight strategic dimensions (p. 28).

In the area of institutional transformation, Kezar and Eckel (2002) and Eckel and Kezar (2003) have done considerable work analyzing what factors are important in implementing and sustaining institutional transformation and note that "much of the literature presents change strategies as isolated, distinct actions and does not present strategies as systemic, concurrent, and interdependent" (Kezar and Eckel, 2002, p. 296). Their research, conducted with six US universities over a period of four years, formed the basis for a 
series of research publications that discuss five core strategies and additional sub-strategies that institutions should consider in undertaking a transformation endeavour.

When combined, Garrison and Vaughn (2013), Taylor and Newton (2013), Lim and Wang (2017), and Kezar and Eckel (2002) show a substantial overlap in what they identify as essential components, resulting in a set of 21 components that emerged as critical to a successful initiative of blended learning or institutional change. Our study builds on the work of Lim and Wang (2017), Lim et al. (2019), Kezar and Eckel (2002), and Eckel and Kezar (2003) to form the basis for a tool to assist institutional self-assessment of OEP progress.

\section{Methodology}

This study used a self-study methodology. Self-study is employed for "studying professional practice settings" (LaBoskey, 2004, p. 817), where professionals situate themselves as both the researchers and the focus of the research process. In the context of this research, the self-study methodology was a way to examine our individual OEP experiences at our home institutions and then discuss these experiences collectively using a critically reflexive collaborative approach (Hamilton \& Pinnegar, 2014; Pinnegar \& Hamilton, 2009). The selection of institutional samples consisted of both convenience and purposive samples of five heterogenous public postsecondary institutions. The variations among the institutions included type of institution (research university, online teaching university, open learning university, provincial institute, and polytechnic university) and size, as measured by full time enrolments. Additionally, differentiating characteristics and mandates are noted in Table 1.

\section{Table 1}

Characteristics of the Institutional Sample

\begin{tabular}{lcc}
\hline \multicolumn{1}{c}{ Institution } & Description & $\begin{array}{c}\text { Full time domestic } \\
\text { student enrolments }\end{array}$ \\
\hline Justice Institute of BC & $\begin{array}{c}\text { Provincial mandate to provide first responder } \\
\text { education and training. Approximately 30\% of } \\
\text { enrolments are online. }\end{array}$ & 3012 \\
Royal Roads University & $\begin{array}{c}\text { Provincial mandate to offer labour market relevant } \\
\text { programming in the applied and professional } \\
\text { fields; online blended/dual mode }\end{array}$ & \\
Thompson Rivers & $\begin{array}{c}\text { Dual mode (campus/online): campus-based } \\
\text { programs and legislated mandate to provide } \\
\text { University }\end{array}$ & $\begin{array}{l}\text { open learning; separate oversight council for } \\
\text { open learning } \\
\text { Research- and teaching-focused university; both } \\
\text { in-person and online course offerings }\end{array}$ \\
$\begin{array}{l}\text { University of British } \\
\text { Columbia, Vancouver } \\
\text { campus }\end{array}$ &
\end{tabular}


Kwantlen Polytechnic University
Polytechnic teaching university with applied and academic programs; in-person, blended, and online course offerings

Note. ${ }^{\text {a }}$ Enrolments from the Ministry of Advanced Education, Skills and Training (2019)

The criteria for including the institutions were the following: (a) the presence of activity in OEP at the institution as evidenced through BCcampus-funded open textbook initiatives or other OEP activities (e.g., open courses and open faculty development), and (b) the availability of an informant (Creswell, 2007) at the institution who had participated directly in or led an OEP initiative to be part of the research team. Through the engagement of researchers from different disciplines and institutions, the collaborative approach facilitated by our self-study methodology clarified perspectives, revealed multiple points of view, and allowed us to consider alternative explanations (Louie et al., 2003).

\section{Research Questions}

The following research questions framed this study:

1. How do five British Columbian postsecondary education institutions advance and sustain their efforts in OEP?

2. What can we bring to the surface as important components or efforts in successful institutional OEP initiatives in order to guide other institutions?

3. How can an institutional self-assessment tool developed for self-assessment and evaluation of institutional OEP initiatives be improved?

\section{Data Collection and Analysis}

The self-study methodology (Hamilton \& Pinnegar, 2014; Pinnegar \& Hamilton, 2009) used to investigate the research questions involved a three-part process. First, a self-assessment tool (https://oepimpact.opened.ca/isat/) consisting of Likert-scale and open-ended questions was created based on 21 components outlined in the literature review. The tool was piloted with two of the researchers to clarify questions and assess its feasibility and to identify additional areas for further exploration. Two additional questions were added as a result of this pilot. A complete version of our survey (licensed CC BY) to facilitate adaptation to multiple contexts) can be viewed online (https://oepimpact.opened.ca/isat/).

We then filled out the revised survey form. In our responses, we were each asked to provide evidence or an explanation of our responses to each question. Once completed, we were also asked to identify an additional knowledgeable stakeholder/person at our institution to help correct for bias by critiquing and verifying the responses. A number of changes were made based on these reviews and incorporated by each of us into our respective responses.

In the second part of the process, we together reviewed all five institutional survey responses. Because of the variation among types of institutions and our respective OEP initiatives, we extensively explored the 
description, comparison, analysis, and theorizing of developments at each institution (Bazeley, 2013), both within the contexts of our individual institutions and by comparing across the five participating institutions. The collaborative nature of the inquiry enabled us to employ successive stages of both individual and collaborative analysis to arrive at consensus on four key themes and to enhance the validity of the findings. Both multiple sources of data as provided in each of the surveys and the shared insights gained through sharing and collaborating among multiple researchers supported the triangulation of data sources and researchers (Patton, 2002).

Finally, in the third part of the self-study process, we undertook a series of five, extended (approximately one-hour) semi-structured discussions among ourselves to discuss the four themes. These discussions were audio-recorded and transcribed for the purpose of analysis. We were each assigned a transcript and followed the describe, compare, relate, extend, and explain process to further analyze each theme in conjunction with the survey data. Each transcript analysis was then reviewed and annotated by another research team member, who made adjustments as needed.

\section{Findings}

This paper will discuss four themes that emerged across all five institutions from the survey data and that formed the topics for our recorded discussions: advocacy, policy, leadership, and institutional culture. These themes describe dimensions that we found need to be considered in undertaking and assessing the progress of OEP initiatives.

\section{Advocacy}

Advocacy can be defined as efforts to effect and support change in the organization toward adopting and implementing OEP. A challenge with describing advocacy was the increasing breadth of meanings of the term when we examined it more closely in the transcript analysis. In the examples discussed, advocacy among institutions ranged from active forms such as lobbying, promoting OEP to faculty and department chairs, facilitating learning sessions, and other such activities to less active forms such as verbally endorsing early OEP initiatives, developing enabling policies, and making funding available. Its objectives varied from lower education costs for students, particularly in relation to open textbooks, to pedagogical benefits or, more widely, access to learning as part of a social justice mandate. These purposes varied depending on which stakeholder group was undertaking advocacy. For instance, students focused mainly on textbook costs, whereas faculty explored alternative pedagogical models using open educational resources, and some senior administrators saw a political advantage in adopting an OEP stance.

In locating sources of advocacy, we found that common sites of its appearance at early stages of organizational change resembled an internal "third place" or third space (Gutiérrez et al., 1999; Oldenburg, 1999). These spaces consisted of informal groups or committees usually drawn from the middle ranks of the organization, such as centres for teaching and learning, libraries, bookstores, teaching and/or research faculties, and instructional support areas. These spaces, at least at the early stages, operated without formal sanction. They also included activities at more granular levels in the institution. As noted by one of the researchers, "There are probably all kinds of people talking to their colleagues and sharing practices, and 
ideas, and resources. If we're thinking of a small sphere of influence, it could even be one person doing that with another and convincing them to change some of their teaching practices, right? And then that can, kind of, keep going and snowball, potentially." In this way, advocacy is both visible and less visible.

Spilovoy et al. (2020) note that leadership in openness can also originate from students or student organizations, since students are often named as the main beneficiaries of the benefits OER afford. This dynamic was noted in our study, where student leaders exerted a lobbying force on faculty and senior administration with a focus on OER and open textbooks. In addition, some supportive senior administrators took on an advocacy role, typically in response to student lobbying or external funding opportunities, such as open textbook grants. In some cases, OEP were taken up by senior administration as a strategic initiative for increased access and visibility as well as for institutional competitiveness or profile in both domestic and international arenas. As noted by one researcher:

It may be that at a different level of the institution it actually is strategic to be an advocate and supportive of an open initiative, whatever that looks like, because of the context of the institution, the length of time it's been around . . . where it's trying to be in the higher education space. So, I think there's, almost, a political component to advocacy here.

In these ways, advocacy interacts with other dimensions of the study (including policy and leadership), emerges from multiple levels and areas of the institution, and takes various forms that range from active to enabling or permissive.

\section{Policy}

According to a recent report by eCampus Ontario (Skidmore \& Provida, 2019), policy "is a tool with which institutions structure their affairs, determine their organizational stance on particular issues, and create the framework for guiding the direction of their work" (p. 2). We found a general lack of formal policy, or even guidelines, around OEP developed at most institutions included in this study. The development of institutional policy was a possible indicator of the maturity of the OEP initiative, whereby resource allocation and recognition of the importance of these practices within the institution would emerge. For example, the UBC inclusion of OER/OEP work in their promotion and tenure guidelines (Skidmore \& Provida, 2019, p. 15) has been used at other institutions as a model to help support faculty engage and participate in developing OER/OEP.

Both the survey data and researcher discussions revealed tensions encountered around policy development. This was also highlighted by Skidmore and Provida (2019), who found that policy can be perceived as a barrier when it is viewed as being administratively driven and this can cause tensions between grassroots initiatives and formal policy development. For example, we found that open education working groups are important pan-institutional support mechanisms for gathering resources and maintaining the sustainability of initiatives. From a policy perspective, a lack of formal terms of reference or inclusion in institutional governance structures (such as senate recognition) could lead to vulnerabilities if membership or leadership lacked continuity. At the same time, we identified risks to moving from informal or tacit agreements or work on OEP to more explicit ones (such as policy and formal structures). As one researcher pointed out, "I mean, you can do a lot of OEP quietly in the background. ... But if you start to push it and 
put it out into the limelight, it can become a target and become politicized." Another researcher shared that explicit direction on OER development at their institution led to a surfacing of resistance to OER from faculty and/or parents about quality and credibility.

Policy was also discussed in relation to leadership, and it was highlighted that at some point, lack of policy or guidelines could lead to risks around sustainability of initiatives (including lack of commitment to resources) or to vulnerabilities if leadership or key advocates left the institution or moved on. We recognized that policy and leadership might need to intersect to provide support for defined roles and responsibilities related to OER/OEP development. We discussed intersections and tensions between institutional culture, maturity, and evolution of an open education initiative; timing and the way policy is introduced; and awareness of challenges of lack of policy versus top-down policy. We noted that in one institution, policy came more easily when a certain level of grassroots support was attained. As Cox and Trotter (2016) also suggest, culture and agency are key factors in considering the role of policy, as "each university's institutional culture mediates the role that policy plays in academics' decision making” (p. 160).

In relation to OEP, the importance and need for the development of policy and guidelines has been discussed at both the governmental and institutional level, and proponents suggest that policies can inform governance structures, signal leadership support, and provide access to resources (Skidmore \& Provida, 2019). As highlighted by Coolidge and DeMarte (2016), governments, as drivers of policy, can encourage equitable access to higher education by providing support and direction on sustainable OER developments. At the institutional level, Cox and Trotter (2016) argue that the success of OER-related policy is highly dependent on three intersecting components-structure, culture, and agency-and that for OER to be sustainable, policy decisions must be both hygienic (necessary, but not sufficient) and motivational (incentivized). It may be important to identify enabling governance and policy structures as part of the overall framework to better characterize the role of policy in helping to transform institutions.

\section{Leadership}

We discussed leadership within the framing of Kezar (2012), who describes the convergence of grassroots leadership (individuals without positions of authority) and top-down (positions of authority) leadership. As noted above, one of the important ways to enable leadership for an OEP initiative is via open education working groups. Four of the institutions in this study had an open education working group, and despite being at different stages of maturity, these working groups functioned as a form of collaborative leadership. Working groups initiated from or were mentored by cross-departmental middle leadership (faculty/administrators/professional levels). This usually involved or included centralized areas such as libraries, teaching and learning centres, and instructional designers, where members gather informally to share and promote ideas or support initiatives with a variety of possible motivations. This supports Eckel and Kezar's (2003) finding of the role of working groups or cross-departmental teams as an important strategy at the outset and middle stages of institutional transformation in the sense-making process, where old ideas and assumptions and mental models can be transformed.

Over time, the leadership needs to become more formalized to gain more formal senior-level visibility, support, and resources and to be included in strategic planning cycles. We also noted that this formalization may help encourage, mentor, and support subsequent informal groupings. At this stage, a tenuous 
transition may take place between grassroots efforts and ensuring the continuity and sustainability of open education initiatives as they become part of regular practice, or in situations where there is a strong leader but no diffusion, or where there is strong diffusion and no leadership. As one researcher stated,

How do we move forward as an institution trying to infuse this further without that kind of formal recognition of the amount of work that everybody is putting in as well? ... So, what happens if, you know, priorities change? Then how do you maintain that momentum? So, you've got grants, but then you don't actually have the support to build anything.

At the same time, there may be tensions between the degree to which leadership should be formalized and risks and opportunities involved in doing that. In some respects, this echoes Kezar (2012), who described this tension as "kaleidoscope convergence" (p. 745), noting that unlike distributed leadership, convergence presents its own unique challenges, patterns, and levels of success.

The role of student leadership in moving an initiative forward was a gap identified in the survey tool, and we found clear examples where students can and do play a key role in promoting open education and can directly access senior leadership for this purpose. At one university, students organized an open education week and two-day conference; at another university, the student government put forward a proposal to senior administration seeking funding for OER. At the same time, we noted that in some cases, student advocacy created a backlash among some faculty as well as feedback from administration regarding misdirected and poorly timed funding requests-but this also led to guidance from administration as to how move forward using appropriate procedures. This suggests the possible need for mentorship of students in navigating institutional structures and governance. Coordination between informal institutional grassroots initiatives and student leadership could help grow senior institutional leadership support and resources for more formalized structures and policies that can then continue to grow such initiatives. On this point, Baker and Ippoliti (2018) refer to a knowledge gap in how institutions include students formally in OER initiatives and outline several ways that students can be brought into the OER conversation both in and out of class. This includes reaching out to students and engaging with student groups in collaboration and partnership.

\section{Institutional Culture}

Definitions of institutional culture abound, though what we discussed under this heading fits broadly within the definition used by Kezar and Eckel (2002) which was originally proposed by Petersen and Spencer (1991, p. 142) as "the deeply embedded patterns for organizational behavior and the shared values, assumptions, beliefs, or ideologies that members have about the organization or its work" (p. 438). Kezar and Eckel (2002) argue that institutional culture affects how processes of change work in institutions, and we found this to be the case as well. Considering institutional culture is one way to provide a framework to organize and provide meaning to the many specific differences between the institutions in the ways they have started, developed, and sustained OEP initiatives.

Our discussion of institutional culture followed the opening questions: "Are there characteristics of an institution's culture that make it more susceptible to . . going down the path of open? Or are there aspects that would be resistors?" We found several aspects of institutional culture to be drivers or obstacles to OEP at our institutions. 


\section{Institutional Mandate}

Institutions examined in this study that have a commitment to access in their mandates or whose focus is on teaching and learning tend to have more emphasis on OEP at the leadership level and more supports devoted to it. We also noted some disconnect between commitments to open education in institutional mandates or strategic documents and the degree to which those are reflected in policies, resources, or activities.

\section{Reputation}

Reputation is described by whom the institution compares itself to and how it positions itself among peer institutions. Some institutions work to position themselves as innovators and leaders amongst their peers who also emphasize the importance of OEP. In the words of one of the researchers, "I can see a way in which the comparison with external institutions have played in our favour ... not just a desire to do things visibly in this space, but to stay ahead of the pack in this space." But if OEP is not a priority among those institutions viewed as peers, this may not work as a driver.

\section{Centralization/Decentralization}

The degree to which leadership and decision making occur centrally or in decentralized units also affects OEP initiatives and activities. In some institutions, decisions about textbooks and other educational resources are made at a department or program level, and in others these decisions are largely left to individual faculty; each has its own benefits and challenges in promoting OER adoption. In addition, broader policies and practices around OEP may be made and implemented at a central level or may be fragmented across different parts of the institution, leading to uneven efforts. Some institutions have established structures and mechanisms for faculty, staff, and students to communicate and collaborate between disparate units and disciplines, whereas others have not, which makes coming together to move forward on OEP initiatives more challenging.

Other organizational structures also affect OEP at the institutions in this study. Some institutions have more contract and part-time faculty, who may not have the time, the institutional support and resources, or the organizational structures needed to come together to work on OEP initiatives. OEP at some institutions have been driven quite significantly by the advocacy of active student organizations, while other institutions have fewer established structures for strong student advocacy and collaborative activities.

An important challenge in trying to map differences in institutional culture related to OEP is that each of us, as researchers, has only a partial perspective on the large and slippery notion of a broad "culture" within an institution. We each must base our understanding of our institutional culture on our own experiences and role at that institution. This is a limitation of the discussion of our respective institutional cultures; a remedy would require a deep analysis of these cultures by including voices of many people across each institution, which goes beyond the bounds of the current research.

Nonetheless, even with this limitation, we found that institutional culture was a meaningful way to organize some of the many differences amongst our institutions in relation to OEP efforts and would be a fruitful path for further research. Specifically, a more detailed comparison of institutional OEP initiatives based on type of institution or institutional cultures may reveal important insights. 


\section{Summary and Recommendations}

Institutions in this study advance and sustain their efforts through a combination of top-down and bottomup strategies and activities. This paper focussed on four intersecting components-advocacy, policy, leadership, and institutional culture-that emerged as important in advancing the OEP initiatives at these five institutions. These components presented both tensions and opportunities to reflect on the evolution of institutional OEP efforts.

\section{Advocacy}

Both active and less active, visible and less visible forms of advocacy serve to advance OEP, and it is important to recognize that the messaging or the goal of advocacy may vary depending on who is advocating. For example, cost savings may resonate with students, but improved teaching and learning may resonate more with faculty, while institutional visibility and competitiveness may resonate with administrators. In considering OEP as an institutional initiative, there may be value in having a coordinated approach to understanding drivers and targeting messaging for different stakeholders at the institution.

\section{Policy}

Though policy is often perceived as a top-down imperative that can interfere with grassroots initiatives, both the literature and research participants support the notion that policy development can be an overall driver for OEP at the institutional level. Policy was seen to provide a foundation for the sustainability of various initiatives, and it was suggested that one possible addition to the framework would be a "policy environment" category that captures the unique institutional culture and governance structures that would enable OEP to be supported effectively. There is value in identifying enabling governance and policy structures within institutions and facilitating the development of enabling policies and guidelines as open education in the institution and the sector matures and evolves.

\section{Leadership}

While formalizing leadership with grassroots-led efforts may bring risks, the initiative will not be sustainable without visible leadership from senior administration. This signals the importance of creating space for leadership from all levels of the institution, including students, with visible support from senior administration. Furthermore, institutions may need to develop and support student and faculty leadership and advocacy.

\section{Institutional Culture}

Institutions whose mission and mandate focus more on teaching or on wide access to postsecondary education tended to have more OEP activity, as do those which compared themselves to peer institutions with a significant emphasis on OEP. Those with more established and effective organizational structures for collaboration and decision making between units, roles, and disciplines were more likely to have more OEP activity and advocacy than those with more silos or decentralized structures. It is therefore important to target OEP efforts more specifically to institutional mandates or priorities and to leverage or create organizational structures that allow for collaboration among various roles and parts of the institution. 
Undoubtedly, further refinement is needed given that the tool is used in different contexts and at different stages of the institutional journey with OEP. While our research identified gaps in the tool itself, we also observed that the institutional value for using a self-assessment tool may be in highlighting gaps or identifying initiatives which may be hindering other strategies or causing the disproportionate assignment of resources. For example, two of the lowest scoring areas for the institutions in this study were research support and evaluation of the impact of the initiatives. If an institution is operating in an environment where its long-term success depends on sustaining the initiative via external grants or buy-in from senior leadership, this is no doubt an important gap to address.

\section{Limitations}

This study has several important limitations. First, despite the fact that we included verification steps to strengthen the trustworthiness of the data and findings, we are simultaneously researchers and stakeholders at the institutions included in this study and are invested in the success of the initiatives. As such, the question of whether we were compelled to exaggerate or minimize our successes is one we addressed throughout the process. Additionally, this study could be enhanced through including more institutional stakeholders verifying the survey responses. Nonetheless, we underline the value of key informants participating across institutions in dialogue and reflection for creating opportunities to leverage resources and best practices in institutional OEP strategy.

The sample of institutions included in this study is both a strength and a weakness in that it represents a broad range of types of institution and institutional mandates. This means that the findings speak more broadly to a wider range of institutions and to a specific educational jurisdiction, but also may shed less light on the specifics of each type of institution than would a study of a more homogeneous sample. While Eckel and Kezar's (2003) institutional culture typology was not the focus of this study, further researchers may want to explore OEP initiatives more deeply from that angle. They may also find value in examining a sample of similar institutions or in conducting a more granular comparison of institutional types and respective cultures and their OEP efforts.

\section{Conclusions}

As OEP initiatives evolve and mature at institutions, frameworks and tools that can assist in evaluating these initiatives are valuable. Through the use of a self-assessment tool designed to examine institutional OEP efforts at five BC postsecondary institutions, four interconnected and overlapping components emerged: policy, advocacy, leadership, and institutional culture. In this respect, our findings echo Kezar and Eckel (2002), who note that institutional transformation strategies evolve "simultaneously or in clusters rather than sequentially ... balance among strategies is an important principle in transformational change and also linked to the interdependence of strategies" (p. 304). At the same time, we recognize the practical importance of a tool that can help to identify gaps in overall OEP initiative efforts and to redirect resources or develop strategies to address those gaps and achieve this balance, to help realize the potential for institutional OEP to affect transformational change. 


\section{References}

Baker, A., \& Ippoliti C. (2018). Student-driven OER: Championing the student voice in campus-wide efforts. In A. Wesolek, J. Lashley \& A. Langley (Eds.), OER: A Field Guide for Academic Librarians (pp. 239-252). Pacific University Press.

Bazeley, P. (2013). Qualitative data analysis: Practical strategies. Sage.

Coolidge, A., \& DeMarte, D. (2016). OER policy development tool. https://policy.lumenlearning.com/

Cox, G., \& Trotter, H. (2016). Institutional culture and OER policy: How structure, culture, and agency mediate OER policy potential in South African Universities. International Review of Research in Open and Distance Learning, 17(5), 147-164. https://doi.org/10.19173/irrodl.v17i5.2523

Creswell, J. (2007). Qualitative inquiry \& research design: Choosing among five approaches (2nd ed.). Sage Publications.

Cronin, C. (2017). Openness and praxis: Exploring the use of open educational practices in higher education. The International Review of Research in Open and Distributed Learning, 18(5). https://doi.org/10.19173/irrodl.v18i5.3096

Eckel, P. D., \& Kezar, A. (2003). Key strategies for making new institutional sense: Ingredients to higher education transformation. Higher Education Policy, 16(1), 39-53.

https://doi.org/10.1057/palgrave.hep.8300001

Friesen, N. (2009). Open educational resources: New possibilities for change and sustainability. The International Review of Research in Open and Distributede Learning, 1O(5), 1-13. https://doi.org/10.19173/irrodl.v10i5.664

Garrison, D. R., \& Vaughan, N. D. (2013). Institutional change and leadership associated with blended learning innovation: Two case studies. The Internet and Higher Education, 18, 24-28. https://doi.org/10.1016/j.iheduc.2012.09.001

Graham, C. R., Woodfield, W., \& Harrison, J. B. (2013). A framework for institutional adoption and implementation of blended learning in higher education. The Internet and Higher Education, 18, 4-14. https://doi.org/10.1016/j.iheduc.2012.09.003

Griffiths, R., Mislevy, J., Wang, S., Ball, A., Shear, L., \& Desrochers, D. (2020). OER at scale: The academic and economic outcomes of Achieving the Dream's OER degree initiative. SRI International.

https://www.achievingthedream.org/system/files force/resources/atd oer at scale academic economic outcomes feb 2020.pdf 
Gutiérrez, K. D., Baquedano-López, P., \& Tejeda, C. (1999). Rethinking diversity: Hybridity and hybrid language practices in the third space. Mind, Culture, and Activity, 6(4), 286-303. https://doi.org/10.1080/10749039909524733

Hamilton, M. L., \& Pinnegar, S. (2014). Intimate scholarship in research: An example from self-study of teaching and teacher education practices methodology. LEARNing Landscapes, 8(1). https://doi.org/10.36510/learnland.v8i1.680

Hannon, J., Huggard, S., Orchard, A., \& Stone, N. (2014). OER in practice: Organisational change by bootstrapping. RUSC: Universities and Knowledge Society Journal, 11(3), 134. https://doi.org/10.7238/rusc.v11i3.2131

Inamorato dos Santos, A. (2019). Practical guidelines on open education for academics: Modernising higher education via open educational practices (No. JRC115663). Publications Office of the European Union. https://doi.org/10.2760/55923

Inamorato dos Santos, A., Punie, Y., \& Castaño-Muñoz, J. (2016) Opening up education: A support framework for higher education institutions. JRC Science for Policy Report, EUR 27938 EN. Doi:10.2791/293408

Kezar, A. (2012). Bottom-up/Top-down leadership: Contradiction or hidden phenomenon. The Journal of Higher Education, 83(5), 725-760. https://doi.org/10.1353/jhe.2012.003

Kezar, A., \& Eckel, P. D. (2002). The effect of institutional culture on change strategies in higher education: Universal principles or culturally responsive concepts? The Journal of Higher Education, 73(4), 435-460. https://doi.org/10.1080/00221546.2002.11777159

LaBoskey, V. K. (2004). The methodology of self-study and its theoretical underpinnings. In J. J. Loughran, M. L. Hamilton, V. L. LaBoskey, \& T. Russell (Eds.), International handbook of selfstudy of teaching and teacher education practices (pp. 817-870). Kluwer.

Lim, C. P., \& Wang, L. (2017). Blended learning for quality higher education: Selected case studies on implementation from Asia-Pacific. UNESCO. https://bangkok.unesco.org/content/blendedlearning-quality-higher-education-selected-case-studies-implementation-asia-pacific

Lim, C. P., Wang, T., \& Graham, C. (2019). Driving, sustaining and scaling up blended learning practices in higher education institutions: A proposed framework. Innovation and Education, 1(1), 1-12. https://doi.org/10.1186/s42862-019-0002-O

Louie, B., Drevdahl, D., Purdy, J., \& Stackman, R. (2003). Advancing the scholarship of teaching through collaborative self-study. The Journal of Higher Education, 74(2), 150-171. http://www.jstor.org/stable/3648253

Ministry of Advanced Education, Skills and Training (2019). Full-time equivalent enrolments at B.C. public post-secondary institutions. Data Catalogue, Government of British Columbia. 
https://catalogue.data.gov.bc.ca/dataset/full-time-equivalent-enrolments-at-b-c-public-postsecondary-institutions

Oldenburg, R. (1999) The great good place: Cafes, coffee shops, bookstores, bars, hair salons and other hangouts at the heart of a community (2nd ed.). Marlowe \& Company.

Patton, M. (2002). Qualitative research and evaluation methods (3rd ed.). Sage.

Peterson, M., \& Spencer, M. (1991). Understanding academic culture and climate. In M. Peterson (Ed.), ASHE reader on organization and governance (pp. 140-155). Simon \& Schuster.

Pinnegar, S., \& Hamilton, M. L. (2009). Self-study of practice as a genre of qualitative research: Theory, methodology, and practice (Vol. 8). Springer Science \& Business Media.

Rolfe, V. (2012). Open educational resources: Staff attitudes and awareness. Research in Learning Technology, 2O(1). https://doi.org/10.3402/rlt.v20io.14395

Skidmore, J., \& Provida, M. (2019). A place for policy: The role of policy in supporting open educational resources and practices at Ontario's colleges and universities [Research report]. Ecampus Ontario. https://www.ecampusontario.ca/wp-content/uploads/2019/08/2019-08-07-skimoreoe-policy-report.pdf

Social Sciences Feminist Network Research Interest Group (SSFN-RIG). (2017). The burden of invisible work in academia: Social inequalities and time use in five university departments. Humboldt Journal of Social Relations, 1(39), 18. https://digitalcommons.humboldt.edu/hjsr/vol1/iss39/21/

Spilovoy, T., Seaman, J., \& Nate, R. (2020). The impact of OER initiatives on faculty selection of classroom materials. Bay View Analytics. https://onlinelearningsurvey.com/reports/impactofoerinitiatives.pdf

Taylor, J. A., \& Newton, D. (2013). Beyond blended learning: A case study of institutional change at an Australian regional university. The Internet and Higher Education, 18, 54-60. https://doi.org/10.1016/j.iheduc.2012.10.003

Watters, A. (2018, May 4). Invisible labor and digital utopias. http://hackeducation.com/2018/05/04/cuny-labor-open

Weller, M., Jordan, K., DeVries, I., \& Rolfe, V. (2018). Mapping the open education landscape: Citation network analysis of historical open and distance education research. Open Praxis, 10(2), 109126. https://doi.org/10.5944/openpraxis.10.2.822

Wiley, D. (2007). On the sustainability of open educational resource initiatives in higher education. OECD. http://www.oecd.org/education/ceri/38645447.pdf 
How Are We Doing with Open Educational Practice Initiatives? Applying an Institutional Self-Assessment Tool in Five Higher Education Institutions Morgan, Childs, Hendricks, Harrison, DeVries, and Jhangiani

\section{Athabasca \\ University}

(c) 